\title{
UNA SÍNTESIS Y EXPLICACIÓN DE LA INMIGRACIÓN EN ESPAÑA
}

\author{
Prisciliano CORDERO DEL CASTILLO
}

\section{DE LA EMIGRACIÓN A LA INMIGRACIÓN.}

Los desplazamientos humanos o migraciones han sido una constante en el espacio y el tiempo de todos los pueblos. La historia y el suelo español no han sido una excepción a este fenómeno demográfico.

España tradicionalmente ha sido un país de emigración, al menos a partir del descubrimiento de América. Pero, refiriéndonos exclusivamente a los últimos tiempos, en el primer cuarto del presente siglo fueron muchos los españoles que emigraron a las antiguas colonias de Hispanoamérica, principalmente a Argentina, Cuba, Venezuela y Chile. Mas tarde, de 1.960 a 1.975, coincidiendo con el desarrollo europeo posterior a la Segunda Guerra Mundial, la emigración española se dirigió hacia Europa Central: Alemania, Suiza y Francia, principalmente.

Aunque las causas de la emigración pueden ser muchas y de diversa naturaleza, la emigración española ha tenido su origen principalmente en la precaria situación económica que ha sufrido nuestro país hasta los años 70 . Esta situación ha servido de "fuerza impulsora" para que la población española buscara nuevas formas de vida en el extranjero. Por otra parte, las grandes oportunidades que ofrecía Hispanoamérica a primeros de siglo y Europa después de la Segunda Guerra Mundial, han ejercido la "atracción" necesaria para llevar a la población española a estos países.

La crisis económica mundial de 1.973-75 hace que decaiga el interés de la emigración española por Europa, que se de un fuerte retorno de los emigrados y que se inicie en los años 80 un flujo de inmigración hacia España, superior a la propia emigración. En los años 80 la situación económica de España mejora notablemente, y aunque no sea lo suficientemente buena como para ejercer por sí misma atracción sobre la población de otros países, sí lo es su situación geográfica e histórico-cultural, que la convierte en lugar de paso, en la primera etapa de su camino hacia Europa, de la emigración portuguesa, latinoamericana y de otros países norteafricanos y asiáticos, y en lugar de residencia para disfrutar de la jubilación a muchos europeos.

España, en las últimas décadas, se ha convertido de país de emigración, con cerca de tres millones de españoles fuera de sus fronteras en los años 70 , en país de inmigración, con una población extranjera permanente superior a las 500.000 personas.

El número de extranjeros en España es un tema de difícil solución, pues las 
cifras dadas por las distintas fuentes son muy diferentes. Las más bajas son las ofrecidas por las fuentes oficiales: las del Ministerio de Trabajo y Seguridad Social, en base al Registro de Permisos de Trabajo, y las del I.N.E., tomadas de los Censos y Padrones Municipales, que giran en torno a las 360.000 personas; le siguen las del Ministerio del Interior, en las sucesivas rectificaciones hechas por la Dirección General de Policía sobre la situación legal o de ilegalidad de la población extranjera residente en España. La rectificación hecha por la Policía en 1.991 sitúa la población extranjera en 500.000 personas, el equivalente a poco más del 1 por ciento de la población total española. Este parece ser el número más próximo a la realidad.

Por otra parte, están las cifras ofrecidas por trabajos de campo y encuestas, tales como las realizadas por el Colectivo I.O.E., E.D.I.S., H.O.A.C., Cáritas y otros, que elevan el número de extranjeros residentes en España a más de 800.000 personas. Parece que esta cantidad puede estar sobreestimada y que se carece de base científica para justificarla ${ }^{1}$.

\section{LA INMIGRACIÓN EN ESPAÑA EN LOS ÚLTIMOS AÑOS.}

La política restrictiva de inmigración, practicada por Europa y Estados Unidos a raíz de la crisis económica de 1..973-75, hace que muchos emigrantes portugueses, latinoamericanos, africanos y asiáticos elijan a España como lugar de residencia o como primer paso en su camino hacia Europa.

En España, en los años 80, superado el flujo campo-ciudad y con una economía en expansión, cesa la presión laboral en trabajos marginales, tales como el servicio doméstico, la construcción, la minería, la venta ambulante, etc., que pasan a ser ocupados por los extranjeros. Por otra parte, los cambios políticos y la estabilidad social que se registran en España, junto con su clima y sus playas, hacen que acuda a nuestro país una gran afluencia de capitales extranjeros y multinacionales, con sus propios empleados, y muchos turistas, unos de temporada y otros para disfrutar de su jubilación en nuestras costas, llegando también con ellos muchos inmigrantes sin contrato de trabajo.

Según la Dirección General de Migraciones, los extranjeros registrados en España en 1.981 eran 234.081; en 1.991 la cifra ascendió a 283.216. Esta última, por continentes de procedencia, se reparte como sigue ${ }^{2}$ : Europa Comunitaria, 127.396; Europa Resto, 15.555; América del Norte, 13.479; América Central, 9.013; América del Sur, 51,186; Africa, 39.117; Asia, 19.476; Oceanía, 633; No Consta, 7.361.

\footnotetext{
${ }^{1}$ Para más información sobre estas discutidas cifras, consultar a LóPEZ TRIGAL, L.: La Inmigración Extranjera en León, Universidad de León, 1.991, pág. 13-ss.

${ }^{2}$ Ministerio de TRabajo y Seguridad Social: Anuario de Migraciones, 1.993. Ministerio de Trabajo y Seguridad Social, Dirección General de Migraciones. Madrid, 1993.
} 


\section{Diversos tipos de inmigrantes.}

El colectivo de extranjeros viviendo en España, según las distintas fuentes, puede oscilar de los 360.655 que cita el Ministerio de Trabajo para 1.991, a los 834.700 que cita el Informe de la H.O.A.C. en $1.992^{3}$. De estos, el 47,8 por ciento serían de Europa, de Estados Unidos y de otros países desarrollados y el 52,2 por ciento restante provenientes de países menos desarrollados.

Dependiendo de las causas de su migración, podríamos distinguir los siguientes tipos de inmigrantes en España:

a) Asilados políticos y refugiados. Es un pequeño colectivo proveniente de los países de Europa del Este, de Hispanoamérica, de Africa y de Asia.

Aunque existe una cierta resistencia por parte del Estado Español a conceder este tipo de visados, con todo, en 1.990

reconoció la condición de asilados y refugiados a 4.719 personas y en 1.991 a 4.973, de los siguientes continentes:

- Africa: 281, principalmente de Guinea Ecuatorial y Marruecos.

- América: 1.403, de Cuba, Chile, El Salvador y Colombia.

- Asia: 2.851, la mayor parte de Vietnam, Laos, Irán e Irak.

- Europa: 462, de Rumanía y Polonia.

- Apátridas: $1{ }^{4}$

b) Inactivos voluntarios y pensionistas. Provienen principalmente del Reino Unido, Centro y Norte de Europa, Estados Unidos y de los países árabes. Vienen buscando disfrutar de su descanso y del buen clima de las costas españolas del Mediterráneo y de las islas, en un número difícil de cuantificar.

c) Profesionales cualificados. Es un colectivo no muy amplio de personas provenientes de países ricos: Estados Unidos, Europa y Japón, que, por exigencia de sus empresas o para mejorar profesionalmente, vienen a ocupar puestos técnicos o de responsabilidad.

Entre éstos se podrían contar 45.000 europeos, principalmente de Alemania, Francia, Reino Unido e Italia, 5.000 de Estados Unidos y Canadá y 1.436 japoneses, que en 1.991 tenían permiso de trabajo en vigor y que suelen disfrutar de una situación económica por encima de la media nacional.

d) Finalmente, los llamados "inmigrantes económicos". Son la mayoría de los inmigrantes, que vienen buscando un puesto de trabajo en el mundo rico y desarrollado y huyendo de la miseria de sus países de origen. Buscan en la emigración la única vía de supervivencia, aunque sea ocupando los puestos de trabajo peor remunerados y que no quiere nadie.

El colectivo de inmigrantes económicos proveniente del Tercer Mundo está formado, según el Informe de la H.O.A.C. de 1.992 anteriormente citado, por:

\footnotetext{
${ }^{3}$ H.O.A.C.: Situación de los trabajadores extranjeros en España. Madrid, 1992.

${ }^{4}$ Ministerio de Trabajo y Seguridad Social: Ob. cit.
} 


\begin{tabular}{lr}
\hline Asiáticos & 100.845 \\
Africanos & 148.473 \\
Hispanoamericanos & 167.315 \\
Otros, no consta & 18.517 \\
\hline TOTAL & 435.150 \\
\hline
\end{tabular}

Del total de inmigrantes, según el Ministerio de Trabajo, contaban con permiso de trabajo en vigor el 31 de Diciembre de 1.991 los siguientes:

\begin{tabular}{lr}
\hline Portugueses & 11.608 \\
Argelinos & 1.937 \\
Caboverdianos & 1.174 \\
De Egipto & 290 \\
De Gambia & 1.880 \\
De Guinea Ecuatorial & 745 \\
Marroquíes & 41.095 \\
Tunecinos & 212 \\
Otros países & 3.822 \\
\hline ToTAL & 62.763 \\
\hline
\end{tabular}

\section{Distribución espacial de los inmigrantes.}

La distribución de los inmigrantes en el territorio español es muy desigual y está condicionada tanto por el tipo de migración, como por las condiciones y circunstancias económico-sociales de cada comunidad autónoma y las oportunidades que cada una de estas ofrece.

Así, los "inmigrantes económicos" se asientan principalmente en zonas rurales, alrededor de explotaciones agrícolas y mineras, y en zonas urbanas de gran concentración demográfica, donde pueden encontrar trabajo en los servicios y la construcción y verse protegidos por el anonimato. Los asentamientos de estos trabajadores suelen hacerse en colonias o guetos suburbanos, buscando la proximidad cultural y la protección contra la sociedad española, para ellos extraña y, en muchos casos, hostil.

Los inmigrantes profesionales, empleados en su mayoría del capital extranjero, con alta cualificación, se sitúan allí donde se encuentran las multinacionales: Madrid, Barcelona y las zonas turísticas.

Los inactivos y pensionistas extranjeros suelen elegir como lugar de residencia las islas Baleares, Canarias y las costas del Sur y Levante.

Finalmente, los asilados políticos y refugiádos están repartidos por toda la geografía española indistintamente, dependiendo de su condición personal y 
aspiraciones, dándose las mayores concentraciones en las grandes ciudades.

La distribución de los extranjeros residentes en España, por Comunidades Autónomas, en 1.991 era la siguiente:

\begin{tabular}{lrlr}
\hline \multicolumn{1}{c}{ CC.AA. } & № extr. & \multicolumn{1}{c}{ CC.AA. } & № extr. \\
\hline Comunidad Valenciana & 48.722 & Andalucía & 3.071 \\
Extremadura & 4.702 & Aragón & 12.598 \\
Galicìa & 5.774 & Asturias & 81.164 \\
Madrid & 20.631 & Baleares & 6.286 \\
Murcia & 34.911 & Canarias & 2.565 \\
Navarra & 1.748 & Cantabria & 9.412 \\
País Vasco & 2.980 & Castilla-La Mancha & 984 \\
La Rioja & 10.547 & Castilla y León & 6.301 \\
Otros & 60.800 & Cataluña & 47.458 \\
& & TotaL & $\mathbf{3 6 0 . 6 5 5}$ \\
\hline
\end{tabular}

FUENTE: Anuario de Migraciones, 1993.

\section{SITUACIÓN DE LOS "INMIGRANTES ECONÓMICOS" EN ESPAÑA.}

La llegada a España de estos trabajadores, en el mejor de los casos, siempre les supone una tragedia económica, cultural y familiar. Para llegar a España muchos han expuesto sus vidas y la mayoría han hipotecado muchos años de trabajo y libertad, después de haber caído a veces en mafias que los explotan con la promesa de un contrato laboral inexistente.

Este tipo de emigración económica, como lo fue la española en su tiempo, la producen las graves circunstancias en que vive el Tercer Mundo o los también llamados países del Sur: el hambre, las altas tasas de mortalidad y corta esperanza de vida, la falta de vivienda, el analfabetismo, la deficiente sanidad, unas economías endeudadas y unos gobiernos autoritarios o con frágiles democracias.

Huyendo de esas situaciones de precariedad generalizada en sus países de origen, vienen buscando los niveles de vida europeos, que muchos no conseguirán alcanzar.

\section{Situación legal.}

Según estimaciones hechas por el Colectivo I.O.E., a partir de datos del Ministerio del Interior, más del 50 por ciento de los inmigrantes económicos residentes en España serían ilegales.

La entrada en vigor de la Ley Orgánica 7/85 sobre los Derechos y 
Libertades de los Extranjeros en España, "Ley de Extranjería", vino a reforzar los derechos de los trabajadores extranjeros legales, pero dificulta el acceso a la legalización y margina abiertamente a los inmigrantes en situación de ilegalidad.

Los trabajadores ilegales carecen de contrato laboral, no están dados de alta en la Seguridad Social, se encuentran explotados en la economía sumergida y en el trabajo negro, padecen paro, marginación y sumisión a patronos sin escrúpulos, por miedo a ser delatados por estos y ser expulsados de España.

\section{Situación laboral.}

Depende fundamentalmente de su situación legal. Los trabajadores con sus papeles en regla, suelen contar con trabajo, pero en aquellos puestos que no quieren los españoles. Generalmente se trata de trabajos de escasa cualificación, temporeros y mal retribuidos: Construcción, canteras, minas, agricultura, jardinería,hostelería, venta ambulante, servicio doméstico, etc.

La situación laboral de los ilegales suele ser aún más crítica. Generalmente está unida a la economía sumergida y a trabajo negro, con largas jornadas de trabajo para conseguir salarios de subsistencia; sin derecho al paro, ni a la Seguridad Social.

\section{Situación social.}

La situación peor corresponde a los ilegales, pero todos ellos sufren las consecuencias negativas de la emigración, alguno de cuyos indicadores son los siguientes:

a) La separación familiar. Más del 50 por ciento de adultos no viven en familia. Principalmente los africanos, filipinos y muchos hispanoamericanos han emigrado solos, dejando a sus familias en su pais. Otros, los ilegales, si han venido con la familia, tienen que vivir de forma semi-clandestina con su mujer e hijos.

b) Falta de vivienda. Muchas veces porque piensan regresar pronto a sus países, siempre por el elevado costo de la vivienda en España, los inmigrantes se ven obligados a vivir en situaciones de hacinamiento e insalubridad, ocupando dos o tres familias la misma vivienda.

c) Nivel cultural y escolaridad. El nivel cultural de los inmigrantes es muy desigual, dependiendo de los países de origen. Generalizando se puede decir que el nivel cultural más bajo corresponde a los africanos, luego a los portugueses y por último a los hispanoamericanos, entre los cuales se encuentran personas con niveles culturales altos. Con todo, hacer valer su cultura y grado de formación es muy difícil para la mayoría, incluso para aquellos con niveles culturales altos, principalmente cuando se trata de sistemas educativos y culturas distintas a la nuestra.

d) Situación económica. Teniendo en cuenta los criterios para medir la pobreza usados por la C.E., seguidos por el Informe de Cáritas de 1.991, tedríamos que el 50 por ciento de los inmigrantes pueden ser catalogados de 
pobres y un 35 por ciento se encontrarían en extrema pobreza.

La situación de pobreza, unida a la ilegalidad y a la diferencia cultural y en algunos casos étnica, lleva a muchos inmigrantes a la mendicidad, a la delincuencia y a la droga. La situación de la mujer inmigrante es aún de mayor desprotección. Su principal trabajo es el servicio doméstico y su última salida, en casos extremos, la prostitución.

Toda esta compleja situación por la que atraviesan los inmigrantes hace que sectores minoritarios de la población española les traten de forma discriminatoria y que en épocas de crisis económica, como la actual, aflore un fuerte sentido xenófobo. 